\title{
CAPACIDAD PREDATORA DE TROFOZOITOS DE Trichomonas hominis PARA DESTRUIR Y/O FAGOCITAR A Blastocystis hominis
}

\section{PREDATORY CAPACITY OF TROPHOZOITES OF Trichomonas hominis TO DESTROY AND/OR PHAGOCYTOSE Blastocystis hominis}

\author{
Rito Zerpa Larrauri ${ }^{1,2}$, Alina Huiza ${ }^{2}$, Celia Paucar ${ }^{2}$, Yrma Espinoza ${ }^{2}$, César Cabezas ${ }^{2,3}$
}

Trichomonas hominis es un protozoario considerado comensal del intestino grueso (1) que no invade la mucosa; el trofozoito mide entre 8-14 um, con tres a cinco flagelos, y uno que se extiende a lo largo de la membrana ondulante y emerge en el extremo posterior. Posee un núcleo ovoide con cariosoma central, no se conoce el estadio de quiste. Blastocyctis hominis es un protozoario que puede tener entre 2 a más de 100 um de tamaño.

Es frecuente encontrar coinfección de parásitos intestinales ${ }^{(2)}$; sin embargo, si bien se ha descrito interacción de parásitos en el tracto vaginal ${ }^{(3)}$, en la literatura mundial no se ha encontrado referencias de la capacidad predatoria de trofozoitos de Trichomonas hominis, en casos de coinfección con Blastocystis hominis en tracto digestivo.
En estas imágenes se muestra la capacidad predatora de los trofozoitos de Trichomonas hominis para destruir y/o fagocitar a Blastocystis hominis. Para poder evidenciar esta capacidad se realizó un estudio observacional y descriptivo en el Instituto Nacional de Salud del Niño y el Instituto de Medicina Tropical "Daniel Alcides Carrión" de la Universidad Nacional Mayor de San Marcos en Lima, Perú.

Se trabajó con trofozoitos de Trichomonas hominis en coinfección con Blastocystis hominis procedentes de muestras fecales humanas, en medio de cultivo de Pavlova modificado. La capacidad predatora de T. hominis contra Blastocysstis hominis se observó al examen microscópico en montaje húmedo, imágenes que fueron registradas en microfotografías y videos (Figuras 1,2,3,4,5,6 y 7 ).

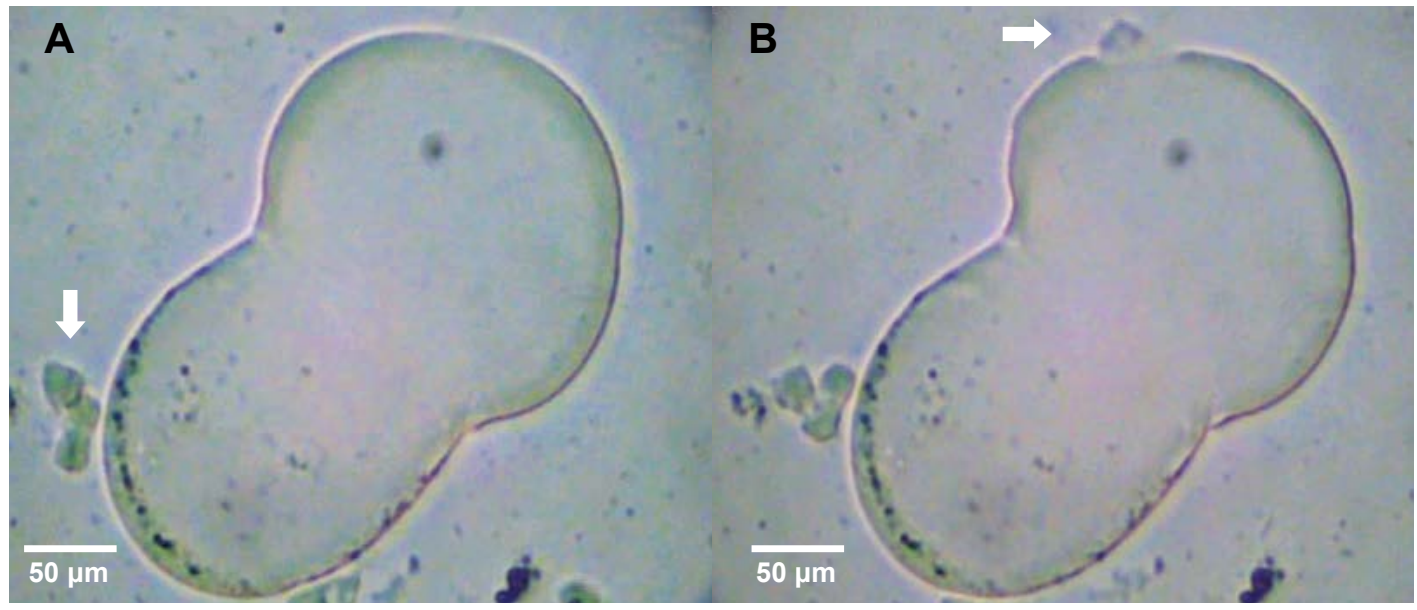

Figura 1. A) Se observa un Blastocystis sp. gigante y trofozoitos de Trichomonas hominis en su periferie. B) En la parte superior se aprecia un trofozoito de Trichomonas penetrando y rompiendo la pared de Blastocystis $s p$. gigante - flecha horizontal; además se aprecia al lado izquierdo del Blastocystis sp. a una Trichomonas en proceso de división atipica, fisión binaria transversal - flecha vertical. (video 1)

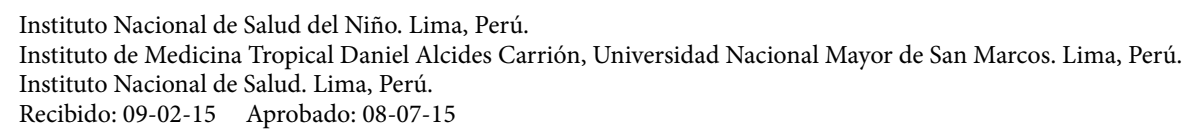

Citar como: Zerpa Larrauri R, Huiza A, Paucar C, Espinoza Y, Cabezas C. Capacidad predatora de trofozoitos de Trichomonas hominis para destruir y/o fagocitar a Blastocystis hominis. Rev Peru Med Exp Salud Publica. 2016;33(1):168-70.doi: 10.17843/rpmesp.2016.331.2019 


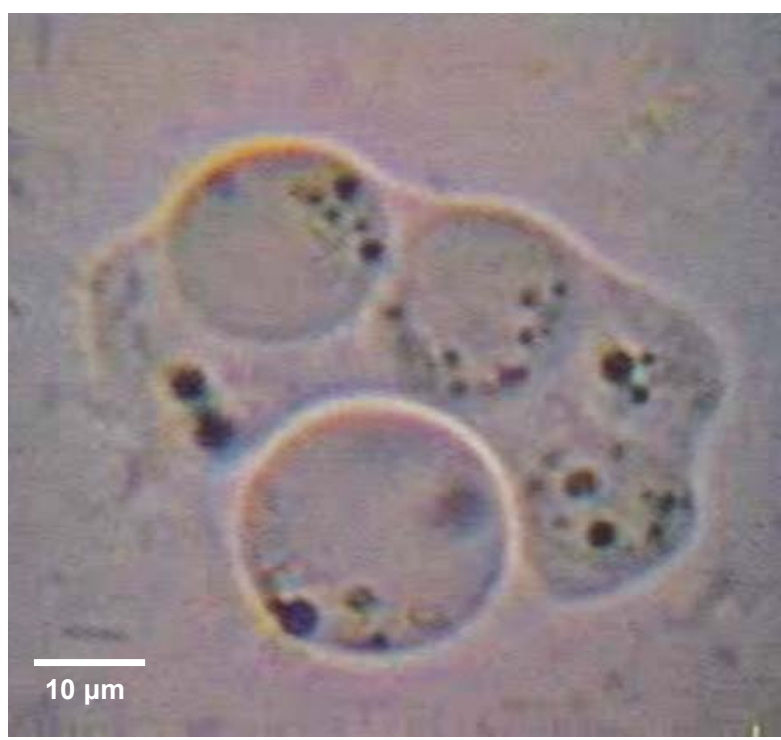

Figura 2. Se observa un trofozoito de Trichomonas hominis con cuatro Blastocystis fagocitados y doble intento de fagocitosis de Blastocystis por un citostoma elástico de Trichomonas, ubicado al final de la membrana ondulante, que aparece y desaparece en la fagocitosis (video 2)

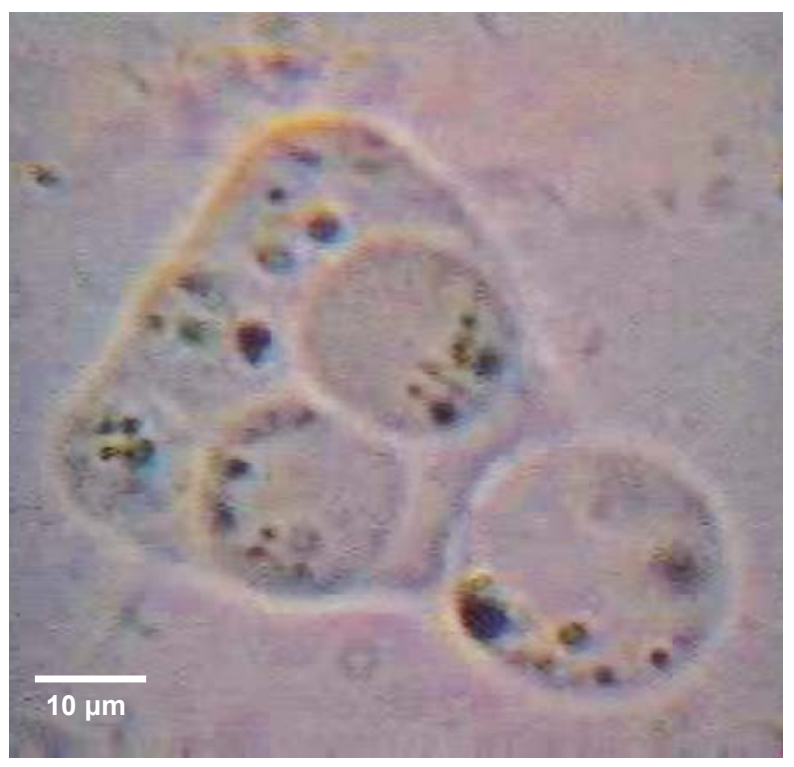

Figura 4. Se observa un trofozoito de Trichomonas hominis con cinco Blastocystis fagocitados e intento de fagocitosis de Blastocystis por un citostoma elástico de Trichomonas, además se observa la expulsión de un Blastocystis (video 4)

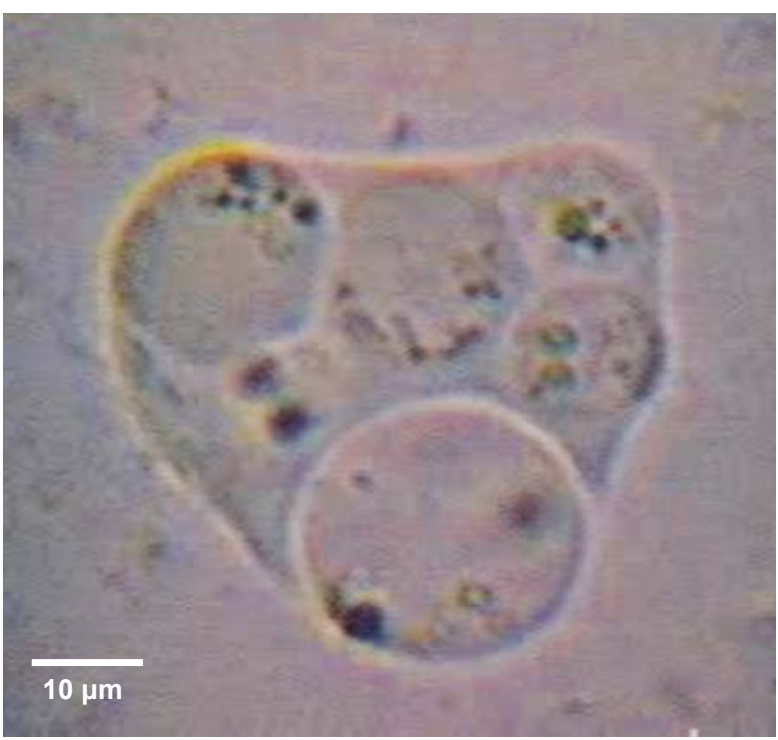

Figura 3. Se observa un trofozoito de Trichomonas hominis con cinco Blastocystis fagocitados e intento de fagocitosis de Blastocystis por un citostoma elástico de Trichomonas (video 3)

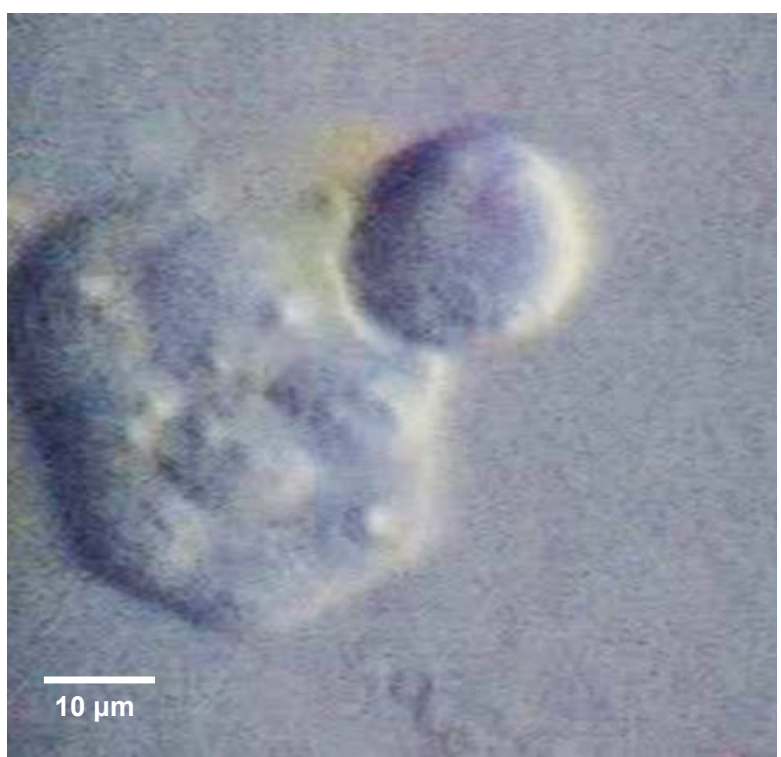

Figura 5. Se observa un trofozoito de Trichomonas hominis con ocho Blastocystis fagocitados e intento de fagocitosis de Blastocystis por un citostoma elástico de Trichomonas; además se observa la expulsión de un Blastocystis (video 5) 


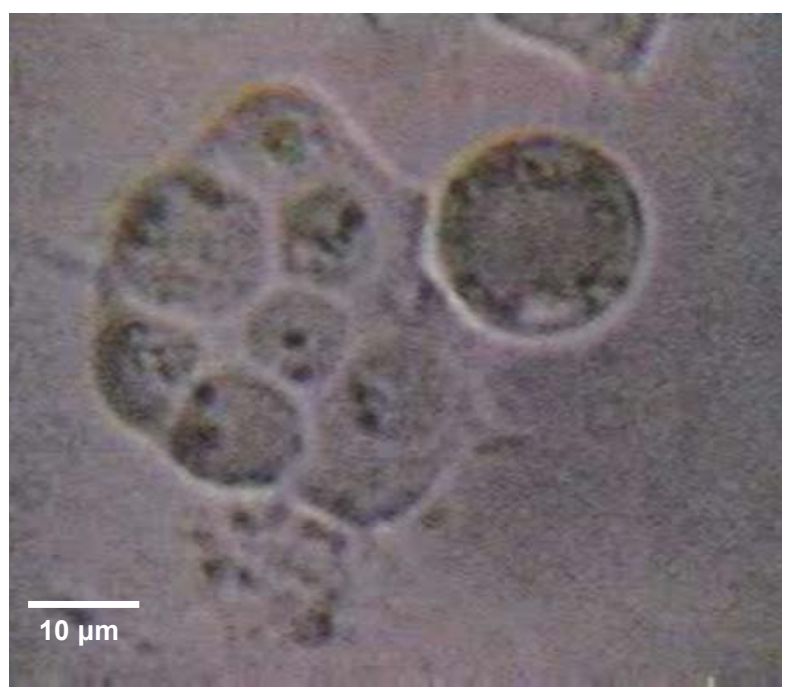

Figura 6. Se observa un trofozoito de Trichomonas hominis con siete Blastocystis fagocitados e intento de fagocitosis de Blastocystis por un citostoma elástico de Trichomonas (video 6)

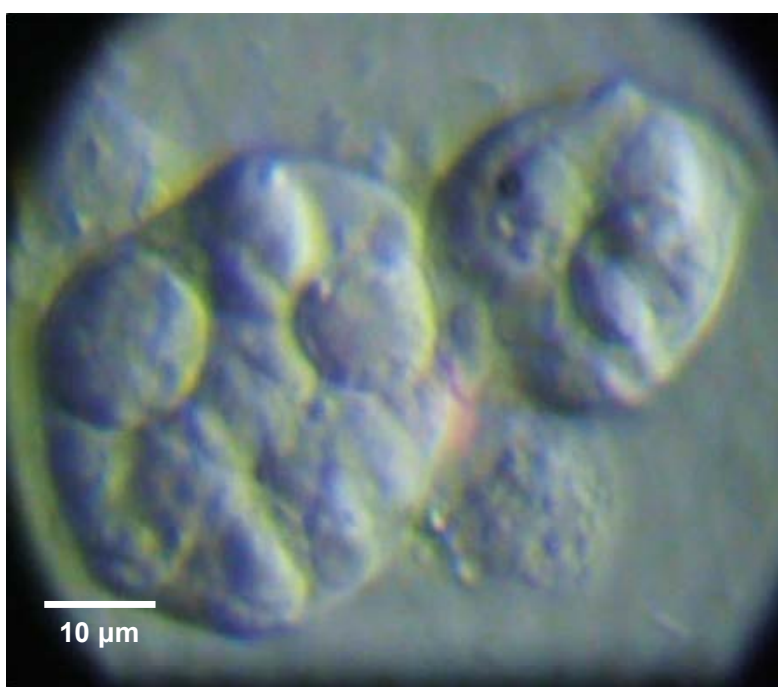

Figura 7. Se observa un trofozoito de Trichomonas hominis con siete Blastocystis fagocitados (izquierda) y una Trichomona más pequeña con tres Blastocystis fagocitados (derecha) (video 7)

\section{REFERENCIAS BIBLIOGRÁFICAS}

1. Aucott JN, Ravdin JI. Amebiasis and "nonpathogenic" intestinal protozoa. Infect Dis Clin North Am. 1993; $7(3): 467-85$.

2. Haghighi A, Khorashad AS, Nazemalhosseini Mojarad E, et al. Frequency of enteric protozoan parasites among patients with gastrointestinal complaints in medical centers of Zahedan, Iran Trans R Soc Trop Med Hyg. 2009 May;103(5):452-

4. doi: 10.1016/j.trstmh.2008.11.004.

3. Street DA, Wells C, Taylor-Robinson $\mathrm{D}$, Ackers JP et al. Interaction between Trichomonas vaginalis and other pathogenic micro-organisms of the human genital tract. Br J Vener Dis. $1984 \mathrm{Feb} ; 60(1): 31-8$.

Correspondencia: Rito Zerpa Larrauri

Dirección: Av. Rio Marañón 436, Los

Olivos. Lima, Perú.

Teléfono: (511) 528-1538

Celular: (511) 9977-51043

Correo electrónico:rzerpa43@yahoo.com

\section{La ciencia al servicio de la población}

\section{Ahora compartimos con el ciudadano publicaciones científicas de la Revista Peruana de Medicina Experimental y Salud Pública}
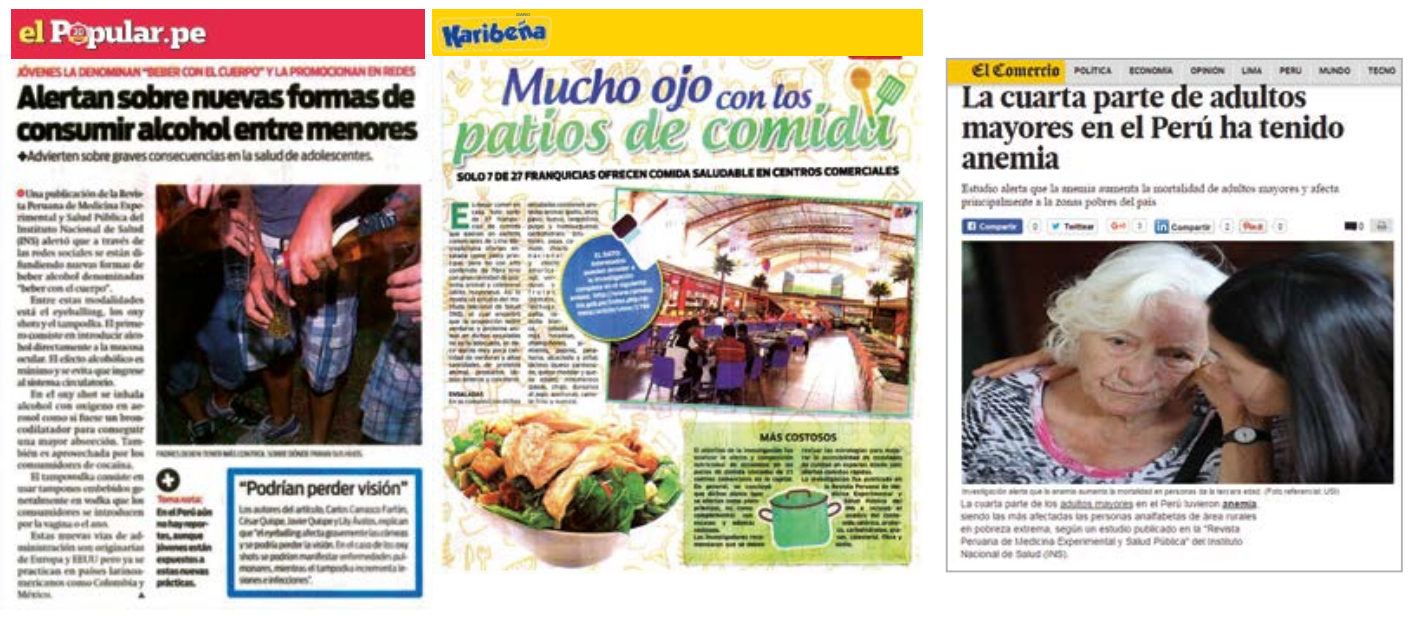